mercury should be given, I shall not venture an opinion; but $I$ would venture to observe (and the remark applies equally to opium) that, if given at all, why do we continne, in a disease of such fearful urgency as cholera, to administer mer. cury and opium in solid forms in preference to liquid? In all other diseases it is in a great measure immaterial whether medicines act a few hours sooner or later. In cholera, on an hour's time, or less, may hang the alternative of life or death. True, it may be said that both calornel and opium are more easily retained on the stomach, and less easily thrown off, than liquid corrosive sublimate and laudanum, \&c.; but we consider the disadvantage of the liquid form less than the advantage, since we can repeat the dose incessantly till something is at last retained.

The propriety of administering emetics is another point, open (we conceive) to no small doubt. An emetic usually reduces both the temperature and the vital energy, and hence, unless its use is counterbalanced by other advantages, could not be recommended; but persons, for whose judgment we entertain respect, think that the succussion of vomiting may have a beneficial effect on the liver and the nervous system. I confess, that so far as my own observation has extended, I have seen no unequivocal positive evidence of good effects from vomiting, nor can I allege that I have seen any of a contrary kind.

Some time last year, I suggested elsewhere,* that at the origin of any epidemic, attention should be given by medical men, naturalists, \&c., whether there be any coetaneous murrain among animals, or blight of vegetation. It is a fact, that there has been a considerable mortality, for two or three years past, among cattle, and the fact of the potato-blight in Europe is a fact by no means unimportant. Animals and vegetables living, if I may express myself so, more naturally than mankind, sooner feel and manifest the influence of any epidemic virus, from the agency of which man's artificial habits and precautions for a time shelter him. Cholera may just be named and considered a. man-blight, possibly of the same origin as the potato-blight. Let us be thankful, that hitherto the mortality has been so much less in the one case than in the other.

Bentinck-street, Manchester-square, Dec, 1848.

ON A CASE OF

MESENTERIC DISEASE WITH DISCHARGE OF FACCES BY THE NAVEL.

By P. A. BOYLE, Esq., M.R.C.S.E., \&c., London.

Eurza S_, a child, six years of age, residing with her parents, in Upper Seymour-street, was brought to me about eight months ago, and from her appearance and syraptoms, seemed to be suffering from mesenteric disease. The enlarged abdomen, general emaciation of the body, hectic fever, capricious appetite, with all the usual concomitants of that disease, were present. The remedial agents tried on such occasions, with change of air, were all resorted to, without the slightest alteration in the symptoms, or benefit to the patient. Hectic sweats, with great debility and diarrhoea, had now brought the child to the lowest ebb, so that I discontinued everything in the shape of medicine, and gave as much nutritious diet as the stomach could bear.

Things went on so until, about three months ago, the belly had attained an enormous size, and the child had not one moment's respite from pain. On minute examination of the part daily at that period, I thought I could perceive the abdominal parietes becoming gradually softer, with a distinct sense of fluctuation, but as to the exact nature of thefluid I could not of course judge. The abdomen still continued increasing in size for another fort night, when the navel began to protrude, became red and inflamed, and a yellow areola round its base left little doubt as to the presence of matter. As the child's sufferings were so intense, and the pain so acute as to keep her constantly crying out, I thought it would be advisable to anticipate Nature, and make an opening in the navel. I introduced a lancet, when a full pint and a half of the most offensive footic matter escaped. A bandage was then applied above and below the umbilical region, with a poultice to the navel. The child experienced great relief, the great tension of the abdomen being now partially removed, and a tiresome cough, which ac companied the case throughout, began to subside. For another fortnight the navel continued to discharge profusely, when I was suddenly called in by the child's mother, who-to use her own expression-fancied the inside had burst; and certainly not without some reason, as I found the child's night-dress and bed completely saturated with thin faces, which kept issuing through the navel, whenever she coughed or made any attempt to sit up in bed, or turn from side to side. Scarcely anything now passed per anum, althongh $I$ frequently admistered mild purgatives. The appetite was much improved and a good deal of food being consumed, the quantity of feculent matter by the unnatural channel was very great. As a dietary system, arrowroot, strong beef-tea, mutton chop, small quantities of wine, and every thing likely to husband the child's health were recommended, and, medicinally, tonics with alteratives were had recourse to. At the end of three weeks from the time my attention was called to the last circumstance, the bowels began to act with more regularity; the motions were passed naturally, and the discharge of faces by the navel was becoming gradually less, and at the present time there is no discharge of any kind from the part. The child is recovering fast; the appetite is excellent, the spirits good, and the attenuated form is regaining its former plumpness.

I merely give the case as it occurred, without comment, it being one of the many in which Nature exercises her reparative powers in lestoring the healthy functions of the system. Drummond-street, Euston-square, June, 1849.

\section{CONSIDERATIONS UPON THE}

CHIEF EVILS RESULTING FROM THE PRESENT STATE OF OUR MEDICAL ORGANIZATION,

SUPPLEMENTAKY TO THE EVIDENCE GIVEN BEFORE THE PARLIAMENTARX COMMTTTEE.

$\mathrm{BY}$ ED W I LEF,

CORRESPONDING AND HONORARY MEMBER OF THE PRINCIPAL EUROPEAN MEDICAL SOCIETIES.

I ATTENDED a medical meeting, which was convened by advertisement, last year, at the Freemasons' Tavern, and, though I was personally unacquainted with any of the gentlemen present, my name was proposed (unexpected by myself) to be added to those of the witnesses who were to give evidence before the parliamentary committee on behalf of the associated surgeons of England. From the lateness of the hour, our attendance in the committee-room having lasted several hours, I was not able, in replying to queries, sufficiently to call the attention of the honourable committee to the prejudicial consequences of the evils which I now more particularly specify; and in adverting, in a few instances, to individuals, I have been chiefly desirous of illustrating by examples the opinions expressed by me, in further corroboration of which I have quoted from the medical journals, and from the evidence of other witnesses, in order that an impartial estimate of the question may be formed.

Steyne, Brighton, June, 1849.

The late Dr. Hope is reported to have repeatedly said, that he would not have the cruelty to bring up his only son to. his own profession; and if the question were asked why this disiuclination should have been expressed in such strong terms by one who had himself attained considerable eminence and practice at a comparatively early age, the reply, with any one acquainted with its condition, would doubtless be, that the profession-which has been justly termed godlike, from the amount of positive benefit it is calculated to confer upon mankind-is in itself honourable, and honoured in countries where the just rights of its members are made compatible with the public welfare by the laws established for its regulation, but that the abuses which have long prevailed in England, in consequence of the irresponsible control exerted by various corporate bodies, whose conflicting interests are opposed to the common weal, have produced its gradual deterioration, which has at length arrived at such a point as to render legislative interference urgently imperative.

This opinion is almost unanimously entertained by impartial persons, who have directed their attention to the subject, and has been expressed by the medical periodicals; and the chief reason why so little progress has been made in the settlement of the important question of medical reform, may be referred to the circumstance, that when inquiries into the state of the profession have been instituted on the part of government, information has been too exclusively sought from gentlemen attached to the ruling bodies, and, consequently, interested in maintaining the actual system, by conceding as little alteration as possible. The question has, moreover, been complisated by the different sentiments held by cortain reformers, from a too partial view as to what alterations are really required,- 